\title{
Educar e qualificar: caminhos e descaminhos da educação de jovens e adultos trabalhadores
}

\section{Resumo}

Sonia Maria Rummert*

Este artigo apresenta reflexões acerca de questôes relativas à qualificação, abordadas em duas perspectivas básicas. Trata-se das concepçôes de qualificação subordinadas à divisão social do trabalho e da decorrente adequação da força de trabalho às necessidades históricas dos diferentes estágios de expansão e consolidação do capital. Posteriormente, será abordada essa temática à luz do materialismo histórico dialético. Para tanto, será apresentada, inicialmente, uma breve retrospectiva histórica da temática da qualificação, coadunada com as necessidades impostas à classe trabalhadora pelo modo de produção capitalista. A seguir, discorre-se sobre as contribuiçôes marxianas à reflexão sobre a mesma temática. Em continuidade, apresenta-se reflexôes preliminares acerca da importância da experiência para a educação de jovens e adultos trabalhadores, na perspectiva da educação comprometida com a emancipação humana.

Palavras-chave: Educação. Classe trabalhadora. Qualificação.

\footnotetext{
*Doutora em Ciências Humanas - Educação, pela Pontifícia Universidade Católica do Rio de Janeiro (PUC/RJ). Professora Associada e integrante do quadro permanente do Programa de Pós-Graduação em Educaçáo da Universidade Federal Fluminense (UFF).
} 


\section{Introdução}

Não são poucos os estudos que evidenciam o fato de que as atuais propostas educacionais para jovens e adultos da classe trabalhadora, formuladas, em nível internacional, de forma coadunada com a lógica dominante e apresentadas sob a promessa de contemplar a todos ao longo de toda a vida, fundamentam-se, na realidade, em uma clara redefiniçáo conceitual que ressignifica, à luz das novas demandas do atual padrão de acumulaçáo capitalista, a permanente expropriação do direito de acesso pleno ao conhecimento.

Essa redefinição, a exemplo da difusão e vulgarização do ideário, hoje hegemônico, vale-se de históricas expressóes e reivindicações da classe trabalhadora, destituídas de seu real significado histórico. Assim, é obscurecida sua gênese, para legitimar novas formas de destituição de direitos que caracterizam, historicamente, as sociedades capitalistas.

Hoje, os conceitos de educação, educação integral, qualificação e formação, utilizados, com frequência e de forma quase indistinta, são ajustados de modo funcional à racionalidade econômica e subordinados à lógica do ethos empresarial (RUMMERT, 2000). Tais conceitos estão, assim, impregnados pela lógica da competitividade e da mercantilização dos direitos sociais e da própria vida, num cenário de subsunção do humano ao mundo volátil da mercadoria.

As particularidades desse processo, no caso brasileiro, trazem à tona um tecido social extremamente complexo e desigual, que abriga desde estigmas das relaçóes escravocratas ainda latentes, até as formas mais livres e modernas de inserção no mercado de trabalho, como, por exemplo, o empreendedorismo.

De acordo com essa perspectiva, podemos afirmar que no breve Século XX (HOBSBAWM, 1994), o Brasil passou de um regime de trabalho assentado na condenação de um povo - o trabalho escravo - para um modelo que vincula, perversamente, a falta de emprego ou de ocupação com incompetência e baixa qualificaçáo individual, num cenário em que a maioria da classe trabalhadora é instada a construir, de modo supostamente livre, sua empregabilidade. Não podemos, ainda, ignorar na análise, a "complexificação de nosso padrão de sociabilidade, tendo em conta tanto as transformaçóes ocorridas nas formas de lutas populares quanto nos padróes de atuação burguesa, bem como as contradiçóes de longa duração que remontam aos traços de nossa colonização. É a essa composição social heteróclita que Oliveira (2003) denominou como "ornitorrinco". 
Nesse complexo tecido social, a adequação da força de trabalho às necessidades históricas dos diferentes estágios de expansão e consolidação do capital e da divisão social do trabalho se associa às necessidades de controle social. Emerge, então, com destaque e recorrentemente, a temática da qualificação, questão que abordaremos neste artigo ${ }^{1}$. Inicialmente, será apresentada uma breve retrospectiva histórica acerca da temática da qualificação, coadunada com as necessidades impostas à classe trabalhadora pelo modo de produção capitalista. A seguir, trataremos da qualificação no âmbito do materialismo histórico dialético. Em continuidade, serão apresentadas reflexôes iniciais acerca da importância da experiência ${ }^{2}$ para a educação de jovens e adultos trabalhadores, na perspectiva da educação comprometida com a emancipação humana (MARX, 1989; RUMMERT, 2008).

\section{Breve olhar retrospectivo sobre a temática da qualificação}

Se, por um lado, na atualidade, a obtenção de qualificação constitui um fetiche no qual, supostamente, reside a soluçấo para os mais distintos problemas sociais, por outro, as referências a ela feitas remontam, na perspectiva de associada preparação adequada da força de trabalho e de controle social aqui adotada, ao século XVIII. O que desencadeará as primeiras formulaçóes acerca da questão será a então iniciante divisão social do trabalho, descrita de forma primorosa por Marx (1983), por exemplo, no Capítulo XIII, do livro primeiro de $O$ Capital.

Como marco dessas formulaçóes, encontramos Adam Smith (1988). Apesar de sua contribuição ter firmado a tese da cultura dos mínimos para a classe trabalhadora, Smith reconheceu, sem subterfúgios, o papel essencial da educação na criação e consolidação das diferenciaçôes sociais. Para ele,

Na realidade, a diferença de talentos naturais em pessoas diferentes é muito menor do que pensamos; a grande diferença de habilidade que distingue entre si pessoas de diferentes profissóes, quando chegam à maturidade, em muitos casos não é tanto a causa, mas antes o efeito da divisão do trabalho. A diferença entre as personalidades mais diferentes, entre um filósofo e um carregador comum da rua, por exemplo, parece náo provir tanto da natureza, mas antes do hábito, do costume, da educação ou formação. (SMITH, 1988, p. 25). 
Ainda em 1776, Adam Smith (1988), na obra Uma investigação sobre a natureza e as causas da riqueza das naçôes, mais conhecida simplesmente como $A$ Riqueza das Naçôes, assinalava a inexorável desqualificação derivada da divisão do trabalho, sublinhando a necessidade de que o Estado assumisse o ônus da educação dos trabalhadores, para fazer frente a referida desqualificação e às novas demandas da produção. Alertava, entretanto, para a necessidade de que a educação dos trabalhadores deveria ser ofertada em doses homeopáticas (SMITH, 1988), baseada em conhecimentos rudimentares, regulada de forma estrita pelas demandas do processo produtivo e pelas necessidades impostas pelo controle social.

Outro legado deixado à temática da qualificação, subordinada à lógica do modo de produção capitalista, foi deixado por Alfred Marshall. Atravessando o século XIX e primeiras décadas do século XX, desenvolve teses que irão, posteriormente, constituir subsídios para a formulação da Teoria do Capital Humano. Para o economista inglês, a educação e a qualificaçâo, compreendida por ele como aprendizagem industrial, constituíam fatores indispensáveis às atividades produtivas.

Tomando como referência a grande indústria que, aquela época já se consolidava na Inglaterra, entendia ser necessária uma preparação prévia (qualificação) para o exercício do trabalho. Tal preparação, bem mais complexa do que a proposta por Smith, deveria ser estruturada em torno de dois conjuntos: o das habilidades específicas e o das habilidades especializadas, como assinala Castioni (2010). A expressão habilidade geral designa "as faculdades, os conhecimentos de ordem geral e a inteligência, que são em diversos graus, propriedade comum em todos os graus elevados da indústria" (MARSHALL, apud. CASTIONI, 2010, p. 80). Já a habilidade especializada refere-se à "destreza manual e [a] o conhecimento dos materiais e processos necessários a determinados fins” (MARSHALL apud CASTIONI, 2010, p. 80).

Não podem ser ignoradas também, nessa breve retrospectiva, as proposiçóes de Frederick Taylor que, vivendo no mesmo período de Marshall, apresenta formulaçôes que divergem em suas concepçôes básicas. Taylor será responsável pelo surgimento da chamada Administraçáo Científica do Trabalho, na qual a questão da qualificação será abordada sob dois enfoques: a qualificação do trabalho e a qualificação do trabalhador. Visava, com suas proposiçóes, aprimorar a produção, na qual as ações improvisadas deveriam ser substituídas por procedimentos científicos os quais, entre outras características, decompunham os movimentos do trabalhador com o objetivo de racionalizar a execução do trabalho. 
O taylorismo propugnava a tese de que os trabalhadores podiam ser distinguidos entre aqueles capazes de exercer atividades intelectuais, aos quais cabiam as funções de planejamento e supervisão, e aqueles aptos apenas às atividades manuais e pesadas, os quais denominavam como de tipo bovino, e que deveriam ser adestrados para o exercício de suas tarefas.

O surgimento da Administração Científica, em que pese a forma desumana e preconceituosa a partir da qual formulava bases da qualificaçáo para a maioria da classe trabalhadora, constitui um marco que repercutirá no mundo ao longo do século XX. A partir de então, sobretudo após o término da Segunda Guerra Mundial, vários estudos voltam-se para a temática. Entre elas, destacamos, aqui, as contribuiçóes da escola francesa, representada pelos sociólogos George Friedman, que empreendeu suas pesquisas a partir da década de 1940, e Pierre Naville, cujos estudos mais relevantes datam da década de 1950.

Friedman (1956), que escreveu, em 1946, o livro Problemas humanos del maquinismo industrial, tido como a obra fundadora da Sociologia do Trabalho, que fará referências ao operário qualificado, ao operário profissional e, particularmente, à habilidade profissional (CASTIONI, 2010). O autor não se filia às teses de Taylor, por entender que suas proposiçóes não concorriam para a elevação do trabalho humano. Ao contrário, em sua obra Onde vai o trabalho humano (FRIEDMAN, 1972), datada de 1952, que resulta de pesquisas realizadas na indústria francesa, apresenta seu conceito de qualificação de forma clara e o associa à concepção de saber que, em escritos posteriores, constituirá a busca por respostas à indagações relativas ao necessário conteúdo das qualificações.

Nas críticas empreendias a Taylor, Friedman sublinhava o fato de que a introdução do automatismo imprimia as empresas da época novas exigências que viriam a resultar em novas formas de divisão do trabalho, as quais, se por um lado superavam aquelas derivadas da produção no período de hegemonia do taylorismo, por outro parcelavam de outras formas os saberes da classe trabalhadora.

Em certa medida, podemos considerar Friedman como um precursor da concepção de competência e formulador de várias características atuais da qualificação oferecida/exigida aos trabalhadores. Nessa perspectiva, cabe assinalar a relação estabelecida entre a qualificação e os conhecimentos técnicos, a inteligência profissional, a aprendizagem ao longo de extensos períodos, a experiência técnica, a capacidade de tomar iniciativa frente aos processos e 
métodos de trabalho, os conhecimentos referentes à matéria que constitui o objeto do trabalho e a consciência profissional.

A relevância do pensamento de Friedman para as atuais discussóes acerca da qualificação e da temática das competências não poderão ser abordadas aqui. Porém, não devem ser minimizadas, particularmente pelo fato de que ao analisar a qualificação necessária aos processos de trabalho, na primeira metade do século XX, abordava-a como expressão social de algo que ia além do chão da fábrica. Assim, identificava as amplas relações pedagógicas (GRAMSCI, 1999; RUMMERT, 2007) envolvidas na formação do trabalhador, destacando que esse era permanentemente formado, inclusive em seu tempo supostamente livre.

A análise do sociólogo francês se reveste de fragilidades, entre as quais pode ser brevemente mencionada a crença na democracia capitalista, considerada capaz de assegurar, pelo ensino e pela qualificação, a mobilidade social perfeita a qual, por sua vez, dependeria, estritamente, das capacidades dos trabalhadores. Essa perspectiva era partilhada com o estudioso francês Pierre Naville, e foi explicitada na obra Tratado de Sociologia do Trabalho (FRIEDMAN; NAVILLE, 1973), elaborada em conjunto com George Friedman e publicada em 1962.

Tal fragilidade também decorre do fato de que foi superestimado o poder normatizador do trabalho prescrito e menosprezada a importância do trabalho real, que constitui a verdadeira expressão do saber e da não submissão absoluta do trabalhador ao regime de exploração e alienaçáo do trabalho no modo de produção capitalista.

Nesse sentido, Friedman, Naville e os teóricos que sucederam, sobretudo aqueles que hoje, predominantemente dentro da ordem, formulam as bases da formaçáo da classe trabalhadora segundo a lógica das competências, parecem ignorar o fato de se por um lado parte significativa dos conhecimentos produzidos no trabalho é expropriada pelo capitalismo, por outro, há uma parte que "permanece inapropriável, inalienável" pelos trabalhadores (FIDALGO; FIDALGO, 2007, p. 21).

São muitos os limites epistemológicos das análises até aqui referidas, bem como dos autores que vêm tratando do tema e que não podemos mencionar em virtude dos limites desta exposição. Não devemos, porém, deixar de destacar, neste breve retrospecto, as atuais contribuiçóes de Philippe Zarifiam, aos quais faremos referência a seguir. 
No trabalho $O$ modelo de competência: trajetória histórica, desafios atuais e propostas, Zarifian (2003, p. 37) afirma que não há distinções conceituais entre qualificação e competência, "a não ser para se dizer que o modelo de competência especifica, hoje, de maneira nova, a qualificação”.

O autor ressalta que a produçáo centrada nos postos de trabalho, caracteriza-se pelo fato de haver uma precedência do trabalho sobre aquele que o exerce e que, ao contrário, nos processos produtivos centrados nas competências, o trabalho constitui uma expressão direta da potência e da ação do trabalhador.

Em decorrência, seria superada a distância, de caráter subjetivo, entre as tarefas e o trabalhador. No modelo das competências, o trabalhador desenvolve uma implicação subjetiva com o seu trabalho, o que, devemos sublinhar, constitui um dos grandes focos da atual qualificação, coadunado com os interesses do capital e de sua permanente necessidade de construção e manutenção da hegemonia.

Entrelaçando qualificação e competência, Zarifiam (2003, p. 51) ressalta que "alguém é tanto mais qualificado (e, portanto, melhor remunerado) quanto mais autônomo no seu trabalho". Em obra anterior, o autor defende a tese de que não são os diplomas ou os saberes que são julgados na atualidade, mas sim a capacidade do indivíduo manifestar competências e produzir efeitos importantes no trabalho (ZARIFIAN, 2001).

Atualmente, a noção de competência constitui uma das ideias-força que organiza a pedagogia do capital, tal como apropriada, de forma hegemônica, pelas forças dominantes, tanto no plano conceitual quanto prático. Se, anteriormente, a intervenção do capitalismo, no âmbito educacional, se dava de forma talvez menos evidente (a exceção do formato fordista da escola de massa), agora a permeabilidade do conceito atravessa, sem fronteiras e igualmente, o espaçotempo produtivo e o espaço-tempo escolar, tornando-se um eixo pedagógico orientador que se pretende de caráter universal. Constituindo referência central na definição de políticas tanto de formação quanto de gestão, tanto no âmbito educacional e quanto no do controle e administração da força de trabalho, a noção de competências, pelo que encobre acerca de suas intencionalidades e pelo que promete como panaceia, coaduna-se com o considerado inevitável processo de expropriação dos trabalhadores e de flexibilização das formas contratuais e do processo produtivo. 
$\mathrm{Na}$ realidade, em todas as proposiçóes aqui brevemente referidas, verifica-se a continuidade do permanente estabelecimento dos mínimos nas propostas de qualificação. Tal característica decorre do fato de que "o saber é força produtiva. A sociedade converte a ciência em potência material" (SAVIANI, 1994, p. 160). De acordo com essa perspectiva, o conhecimento constitui meio de produção e, portanto, na sociedade capitalista, propriedade privada. Sendo força produtiva, é apossado pela classe dominante e não será partilhado livremente com a classe trabalhadora. Para Saviani (1994, p. 160161), "na medida em que o saber se generaliza e é apropriado por todos, entáo os trabalhadores passam a ser proprietários de meios de produção. Mas é da essência da sociedade capitalista que o trabalhador só detenha a força de trabalho".

Nesse quadro assenta todo processo de correlaçáo de forças em que o capital, ao longo dos últimos séculos, tem, por um lado, regulado a seu favor a distribuição de condiçóes de acesso ao conhecimento e, simultaneamente, procurado, a partir das mais variadas estratégias, apropriar-se dos conhecimentos produzidos pelos trabalhadores nos processos de trabalho. Por outro lado, vemos, ao longo desse período histórico, uma intensa luta desses trabalhadores, tanto no sentido de obter acesso ao conhecimento privatizado quanto no sentido de resistir à contínua desapropriaçáo de seus saberes.

Ainda segundo Saviani (1994, p. 161), "aí está a contradição que se insere na essência do capitalismo: o trabalhador náo pode ter meio de produção, não pode deter o saber, mas sem o saber ele também não pode produzir, porque para dominar a matéria precisa dominar algum tipo de saber". É precisamente no bojo dessa contradição que se inscrevem os processos de correlaçáo de forças que vêm definindo, historicamente, os limites e os avanços da educação da classe trabalhadora.

\section{Considerações sobre a questão da qualificação à luz do materialismo histórico dialético}

As teses brevemente referidas na retrospectiva, apesar das mudanças havidas no processo produtivo e no padrão de acumulaçấo, por estarem circunscritas à ordem, não contemplam a questão da qualificação de forma plena. Tal perspectiva é encontrada, entretanto, nos fundamentos do 
materialismo histórico dialético. Se, por um lado, Marx não apresentou formulaçóes claras acerca do conceito de qualificação dos trabalhadores, por outro, podemos encontrar, em seu pensamento, as bases de outra compreensão da qualificação.

Ao analisar o trabalho humano, Marx (1996, p. 115) afirma:

O homem faz de sua atividade vital o objeto de sua vontade e de sua consciência. Ele tem uma atividade vital consciente; ela não é uma determinação com a qual ele se confunda imediatamente. A atividade vital consciente distingue diretamente o homem da atividade vital do animal.

Adiante, ao ressaltar as distinções ontológicas entre os animais e os seres humanos, Marx (1996) deixa claro tal distinção, afirmando que os animais produzem, estritamente, o que é necessário para si e para sua cria, produzindo, portanto, de uma maneira unilateral. De forma inteiramente distinta, "o homem produz de um modo universal [...] o homem produz mesmo quando livre de toda necessidade física e só produz verdadeiramente quando está verdadeiramente livre" (MARX, 1996, p, 116).

Nesse processo criativo, cujo caráter reside na marca consciente da atividade produtiva do homem, se entrelaçam, dialeticamente, as necessidades com a produção dos elementos materiais e imateriais que as satisfazem. Em decorrência, os seres humanos produzem, ao longo de toda a história da humanidade, conhecimentos. Sendo o conhecimento fruto da experiência do trabalho, podemos compreender, também, que a produção do conhecimento é uma ação estritamente humana.

Não é demais assinalar que os seres humanos, em maior ou menor grau, mas sempre, exercem sua capacidade de criação. Como afirma Vigotski, a criaçâa

[...] não existe apenas quando se criam grandes obras históricas, mas por toda a parte em que o homem imagina, combina, modifica e cria algo novo, mesmo que esse novo se pareça a um grãozinho, se comparado às criaçóes dos gênios. Se levarmos em conta a presença da imaginação coletiva, que une todos esses grãozinhos frequentemente insignificantes da criação individual, veremos que grande parte de tudo o que foi criado pela 
humanidade pertence exatamente ao trabalho criador anônimo e coletivo de inventores desconhecidos. (VIGOTSKI apud PRESTES, 2010. p. 76).

Em síntese, é pelo trabalho que os seres humanos apreendem e transformam suas circunstâncias individuais e coletivas de vida. E é na riqueza e contraditoriedade desse processo que todo o conhecimento é produzido e são construídas, historicamente, as diferentes formas de relações pedagógicas, formais, não formais e informais no âmbito em que os seres humanos se educam e se qualificam em cada etapa dos padrōes de acumulação.

Na busca de compreensão da realidade para nela intervir, os seres humanos se veem diante de um limite histórico, como assinala Lefebvre (1979, p. 100):

O pensamento humano pretende possuir a soberania sobre o mundo e o direito absoluto sobre a verdade "infinita”. O pensamento dos indivíduos não pode ter tais pretensóes; é sempre finito, limitado, relativo. Mas essa contradição é resolvida pela sucessão das geraçóes humanas e pela cooperação dos indivíduos nessa obra coletiva que é a ciência

Na teoria marxista, os objetos do conhecimento, que são as manifestaçóes da realidade que se pretende conhecer, embora se diferenciando e se particularizando, o fazem como partes de um complexo de relaçóes que se unificam e constituem uma totalidade. Para Kosik (1978, p. 44), totalidade significa "realidade como um todo estruturado, dialético, no qual ou do qual um fato qualquer (classes de fatos, conjunto de fatos) pode vir a ser racionalmente compreendido". Alerta, ainda o filósofo, que a realidade não é mera soma dos fatos, bem como que todos eles reunidos não constituem a totalidade.

Abandonar a perspectiva da totalidade significa, na rica metáfora de Caio Prado Júnior (2001), em Teoria marxista do conhecimento e método dialético materialista, ver as árvores, mas não perceber a floresta. Nesse sentido, a totalidade (a floresta) é sempre muito mais complexa do que a soma das partes (as muitas árvores que a compóem). Não podemos ignorar, porém, que tanto a totalidade (a floresta), quanto suas partes (as árvores) representam um conjunto de relaçóes e cada um de seus elementos constitui, concomitantemente, uma totalidade e uma parte. Essa perspectiva exige, permanentemente, a abordagem dialética do todo e da parte. 
Podemos, assim, compreender a questão da qualificação como uma síntese de múltiplas determinaçôes historicamente construídas e, ela própria, também historicamente construída. Ainda segundo Prado Jr. (2001, p. 28), podemos afirmar que não "há capital fora das relaçôes em que o capital figura entrosado com o fato da compra da força de trabalho, dos meios de produçáo etc". Em decorrência, podemos compreender que "não há força de trabalho (em termos capitalistas) ou quaisquer outros elementos do sistema à parte desse sistema e fora das relaçóes em que eles entre si se articulam" (PRADO JR., 2001, p. 29).

\section{A experiência da classe trabalhadora como fundamento político-pedagógico}

Os seres humanos se caracterizam, entre outros aspectos, pela busca constante de acesso ao conhecimento coletiva e historicamente produzido pela humanidade. Essa busca ocorre a partir de percursos individuais, mas, sobretudo, coletivos, em situaçóes pedagógicas propiciadas em diferentes espaços formativos, não se reduz à lógica que dá sustentação às teses relativas ao "aprender ao longo da vida", hoje tão em voga e já analisadas de forma consistente na literatura crítica pertinente à área.

Para que os processos de aprendizagem dos trabalhadores se coadunem, efetivamente, com seus interesses de classe, devem ser regidos pelo propósito pedagógico de construção da emancipaçáo humana. Dessa forma, devem ser empreendidos a partir das vivências da classe e em diálogo com a classe. Faz-se necessário, portanto, compreender que os jovens e adultos trabalhadores não se educam formalmente, não se qualificam, efetivamente, quando desencarnados de suas realidades socioculturais e históricas, como é corrente na maior parte dos sistemas educativos. Ao contrário, é essencial que integrem os processos formativos na condição de sujeitos individuais e coletivos, que criativamente constroem a história de seu tempo, mesmo quando silenciados pelos discursos dominantes e apartados das condiçóes efetivas de acesso aos bens materiais e simbólicos produzidos por eles próprios.

Abre-se aqui um caminho para a compreensão de questôes de caráter teórico-metodológico fundamentais, que pressupóem avançar a partir da percepção de seus estreitos vínculos com a problemática política que atravessa os sistemas de ensino, e, no caso específico de que tratamos, da qualificação dos trabalhadores, como expressão das contradiçôes sociais. Essa perspectiva 
de análise da realidade da educação de jovens e adultos trabalhadores - aqui abordada como elevação de escolaridade e qualificação destinada às frações mais destituídas de direitos da classe trabalhadora - é evidenciada por Thompson (2002) em fecunda contribuição. Ainda na década de 1960 o autor afirmava:

\begin{abstract}
O que é diferente acerca do estudante adulto é a experiência que ele traz para a relação. A experiência modifica, às vezes de maneira sutil e às vezes mais radicalmente, todo o processo educacional; influencia os métodos de ensino, a seleção e o aperfeiçoamento dos mestres e o currículo, podendo até mesmo revelar pontos fracos ou omissóes nas disciplinas acadêmicas tradicionais e levar à elaboraçáo de novas áreas de estudo (THOMPSON, 2002, p. 13, grifo nosso).
\end{abstract}

A concepção acerca dos processos educativos comprometidos com a emancipação humana se apresenta muito distante da realidade da maior parte dos espaços educativos formais em que ocorrem a açóes relativas à educaçáo e/ou qualificaçáo profissional de jovens e adultos trabalhadores. Na realidade, na maioria das vezes, ela é concebida e se organiza de acordo com valores, normas, necessidades e propostas construídas com base em fundamentos que reproduzem, a partir de muitas mediaçóes, as profundas assimetrias de poder que caracterizam as diferentes fases de consolidação e expansão do modo de produção capitalista. Nessa perspectiva, cabe aos trabalhadores jovens e adultos apenas aceitar o instituído e "desejar" obter êxito e avançar no caminho que lhes é oferecido unilateralmente por uma formação que se configura como mediadora dos interesses dominantes, a partir de referências conformadas à ordem. Nesse cenário, embora seja inerente ao ser humano o ato de aprender, as propostas educativas se organizam, unicamente, a partir do pressuposto da ignorância do aluno e da necessidade de adequá-lo às demandas do processo produtivo.

Agudizam-se, assim, impasses cuja origem podemos situar, como destaca Thompson (2002, p. 36), no período que se seguiu à Revoluçâo Francesa:

Durante um século ou mais, a maior parte dos educadores de classe média não conseguia distinguir o trabalho educacional do controle social, e isso impunha com demasiada frequência uma repressão à validade da experiência na vida dos alunos ou a sua própria negaçáo [...]. O resultado foi que a educaçáo e a experiência se opunham uma à outra. 
A educação de jovens e adultos, que apresenta marcantes características de controle social, se associa, até hoje, à tentativa de imposição de um padrão cultural que nega o valor da experiência da classe trabalhadora. É precisamente no âmbito dessa tensão entre as experiências vividas e o conhecimento socialmente produzido que a educação/qualificação da classe deve constituir espaço que contemple, de forma integrada, as particularidades que caracterizam os jovens e adultos e a universalidade da classe trabalhadora.

Trata-se, portanto, de construir, coletivamente, processos formativos que deem materialidade e atualidade à afirmação formulada por Gramsci (1999), no início do século passado: "antes do operário existe o homem que não deve ser impedido de percorrer os mais amplos horizontes do espírito, subjugado à máquina”.

Tal perspectiva apresenta, como desafio, construir uma nova relação teoria-prática, que efetivamente vá ao encontro de um dos fundamentos da "escola unitária", centrado na "participação ativa do aluno [...] que só pode existir se a escola for ligada à vida" (GRAMSCI, 1979, p. 43). Esse desafio, que nos é apresentado por Gramsci e também por Thompson, enriquece substantivamente a educação de jovens e adultos da classe trabalhadora, sem abrigar simplificaçôes e aligeiramentos na concepção e no fazer pedagógico.

É importante ressaltar que essas reflexões não se assentam em nenhum tipo de idealização dos saberes ou da classe trabalhadora, ou ainda na negação da existência de muitos problemas e dificuldades inerentes à consecução dessas orientaçôes pedagógicas. Ao contrário, pressupomos que, na dinâmica do processo histórico, o que se apresenta incompleto ou impróprio, bem como repleto de desafios, pode impulsionar o novo se todos os envolvidos no processo, colocando-se na condição de construtores coletivos do caminho a ser percorrido, assumirem o compromisso ético-político de forjar uma nova concepção teóricoprática de educação de jovens e adultos. Trata-se, portanto, de aceitar o rico desafio de buscar nas experiências da classe trabalhadora as bases de uma relação que "precisa estar sempre encarnada em pessoas e contextos reais", como nos ensinou Thompson (1987, p. 10).

\section{Conclusão}

Ao compreendermos a questão da qualificação à luz do materialismo histórico, afastamo-nos das proposiçóes de caráter tecnocrático que supóem ser capazes de objetificar a classe trabalhadora e a cada um dos trabalhadores, 
subsumindo-os, de forma estrita, às necessidades históricas do modo de produção capitalista. Tais formulaçôes, que pretendem isolar as concepçôes e ações de qualificação, desconsideram suas íntimas, necessárias e históricas relaçôes tecidas nos sistemas que as engendram. Reproduzem, assim, a metáfora do Barão de Münchhausen que puxava a si mesmo do pântano pelos próprios cabelos, cordóes dos sapatos ou pela crina de seu cavalo, a depender da versão.

Assim o fez Taylor ao supor que os trabalhadores, como bovinos ou gorilas amestrados, podiam ser meramente adestrados e destituídos do ato do pensamento, inerente a todos os seres humanos. Do mesmo modo, Marshall julgou ser possível capturar os saberes dos trabalhadores construídos na vivência do trabalho real e qualificá-los, integralmente, ao nível do trabalho prescrito.

Não é outra a perspectiva que subjaz à atual forma histórica da qualificação da classe trabalhadora segundo a lógica das competências que, sob a aparência da possibilidade de formaçáo de caráter amplo e autônomo, intensifica a captura e o parcelamento dos sujeitos e dos saberes por eles construídos na vivência cotidiana do mundo do trabalho enquanto produção da existência.

Nos exemplos aqui citados, e em todas as iniciativas que tomam os trabalhadores como mera parcela das forças produtivas, não é considerado, em sua inteireza e complexidade, o potencial de criação e resistência implícitos nos processos de produção cotidiana da existência - no trabalho - desenvolvidos cotidianamente, como assinalou Vigotski.

Conforme explicitado por Marx, a teoria e a prática não se divorciam, do mesmo modo que a atividade manual e a atividade intelectual não sáo estanques e dicotômicas e estáo dialeticamente associadas na realização do trabalho e essa associação dialética constitui a gênese da práxis. Porém, em seu desenvolvimento histórico, o capitalismo luta diuturnamente para construir e consolidar tal cisão, gerando a separação entre trabalho manual e intelectual, fazendo com que pessoas distintas se encarreguem de uma ou outra atividade do trabalho, mesmo no atual estágio de produção, aparentemente construído sob novas bases. Na realidade, apesar de grandes variaçóes sofridas em consonância com as mudanças havidas no processo produtivo e no padrão de acumulação, o que permanece intocada é a assimetria de poder entre trabalho e capital que pode ser metamorfoseada, mas constitui um dos elementos fundamentais de sustentação da hegemonia do modo de produção capitalista, em todas as suas fases de expansão e consolidação. 
O que hoje se apresenta como novidade no âmbito da qualificação também é apontado como evidência de que as formulaçôes e análises de Marx sobre os processos de trabalho e sobre a qualificação da classe trabalhadora perderam sentido, tanto por náo considerarem as demandas produtivas da chamada sociedade do conhecimento, quanto por abordarem questóes de ordem geral, que não contemplam, diretamente, temáticas relativas à qualificação.

$\mathrm{Na}$ realidade, tais críticas se apresentam restritas ao plano fenomênico, uma vez que se pautam em bases epistemológicas coadunadas com a lógica do trabalho alienado e prescrito que caracteriza os processos produtivos no âmbito do modo de produção capitalista. As formulaçôes de Marx, ao contrário, não se apoiam no trabalho prescrito, nem tampouco numa perspectiva de formação unilateral, subordinada à lógica da formação da mão de obra necessária às demandas imediatas, tal como é característico do modo de produção capitalista.

As proposiçóes marxianas afastam-se diametralmente das teses que visam, em última instância, à adequação e reprodução imediata e utilitária para postos de trabalho, tal como apregoam as propostas de qualificação anteriormente analisadas. A qualificação do trabalhador, para Marx aponta, necessariamente, para a formação humana ominilateral, na qual fundamenta a educação politécnica ou tecnológica, centrada no trabalho ontologicamente compreendido como princípio educativo.

Assim concebida, a qualificação da classe trabalhadora objetiva assegurar a todos o domínio dos princípios gerais da produção moderna e do manejo das técnicas e instrumentos dos diferentes ramos da produção socialmente necessária. Supera-se, assim, a dicotomia entre dirigentes e dirigidos, entre trabalho intelectual e material, uma vez que a educação não se subordina à lógicas de expropriação de direitos, mas fundamenta-se no conceito marxiano de trabalho enquanto elemento constitutivo do gênero humano livre das amarras do mundo subordinado à lógica das mercadorias.

\section{Notas}

${ }^{1} \mathrm{O}$ texto aqui apresentado constitui a reprodução da conferência "Educar, qualificar: caminhos e descaminhos da educaçâo de jovens e adultos", proferida no encerramento do $5^{\circ}$ Seminário Luso-Brasileiro, Trabalho, Educação e Movimentos Sociais - Jovens e adultos pouco escolarizados: entre a educação e a qualificação. 
${ }^{2} \mathrm{O}$ conceito de experiência é correntemente utilizado na literatura acerca dos processos de ensino-aprendizagem de jovens e adultos. Apesar de polêmico e de ser apropriado sob diferentes perspectivas, como por exemplo, em Dewey e Thompson, nos valemos dele aqui em aproximaçóes iniciais. Cabe, entretanto assinalar, que é necessário empreender estudos que precisem seu real conteúdo à luz do materialismo histórico dialético. Assim sendo, é necessário que sejam também dedicados estudos ao conceito de vivência (perejivaine) em Vigotski, sobre o qual Prestes (2010) chama atenção com pertinência.

\section{REFERÊNCIAS}

CASTIONI, Remi. Educação no mundo do trabalho: qualificação e competência. São Paulo: Farancis, 2010.

FIDALGO, Fernando; FIDALGO, Nara. Refluxos sociais da lógica de competências: o processo de individualização em foco. In: FIDALGO, Fernando et al. Educação profissional e lógica das competências. Petrópolis: Vozes, 2007.

FRIEDMAN, George. Problemas humanos del maquinismo industrial. Buenos Aires: Sudamerica, 1956.

FRIEDMAN, Georges. Où va le travail humain. Paris: Gallimard, 1972.

FRIEDMAN, George; NAVILLE, Pierre (Org.). Tratado de sociologia do trabalho. São Paulo: Cultrix, 1973. 1v. 2v.

GRAMSCI, Antonio. Cadernos do Cárcere: introdução ao estudo da filosofia. A filosofia de Benedetto Croce. Rio de Janeiro: Civilização Brasileira, 1999. 1v.

GRAMSCI, Antonio. Os Intelectuais e a Organização da Cultura. Rio de Janeiro: Civilização Brasileira, 1979.

HOBSBAWM, Eric. Era dos extremos: o breve século XX (1914-1991). São Paulo: Companhia das Letras, 1994.

KOSIK, Karel. Dialética do concreto. Rio de Janeiro: Paz e Terra, 1978.

LEFEBVRE, Henri. Lógica formal, lógica dialética. 2. ed. Rio de Janeiro:

Civilização Brasileira, 1979.

PERSPECTIVA, Florianópolis, v. 31, n. 2, 405-423 maio/ago. 2013

http://www.perspectiva.ufsc.br 
MARX, Karl. O Capital. São Paulo: Abril Cultural, 1983. 1v. 2v.

MARX, Karl. A questão judaica. In: MARX, Karl. Manuscritos econômicofilosóficos. Lisboa: Ediçóes 70, 1989. p. 35-76.

MARX, Karl. Manuscrits de 1844. Paris: Flammarion, 1996.

OLIVEIRA, Francisco de. Crítica à razão dualista: o ornitorrinco. São Paulo: Boitempo, 2003.

PRADO JR., Caio. Teoria marxista do conhecimento e método dialético materialista. São Paulo: Ridendo Gastigat Mores, 2001. Disponível em: <http://www.ebooksbrasil.org/adobeebook/caio.pdf>. Acesso: maio 2009.

PRESTES, Zoia. Quando não é quase a mesma coisa. São Paulo: Autores Associados, 2010.

RUMMERT, Sonia Maria. Educação de qualidade: diferentes visões. São Paulo: Xamã; Niterói: Intertexto, 2000.

RUMMERT, Sonia Maria. Gramsci, Trabalho e Educação: Jovens e adultos pouco escolarizados no Brasil actual. Lisboa: EDUCA, 2007.

RUMMERT, Sonia Maria. Educação de jovens e adultos no Brasil atual: do simulacro à emancipação. Perspectiva, Florianópolis, SC, v. 26, n. 1, p, 175208, jan./jun. 2008.

SAVIANI, Dermeval. O trabalho como princípio educativo frente as novas tecnologias. In: FERRETTI, Celso J. (Org.) Novas tecnologias, trabalho e educação: um debate multidisciplinar. Petrópolis, RJ: Vozes, 1994. p. 147164.

SMITH, Adam. A Riqueza das Naçôes. São Paulo: Nova Cultural, 1988. 1v. (Os Economistas).

THOMPSON, Edward. Formação da classe operária inglês: a árvore da liberdade. Rio de Janeiro: Paz e Terra, 1987.

THOMPSON, Edward. Os românticos: a Inglaterra na era revolucionária. Rio de Janeiro: Paz e Terra, 2002.

ZARIFIAN, Philippe. Objetivo competência: por uma nova lógica. São Paulo: Atlas, 2001

ZARIFIAN, Philippe. O modelo de competência: trajetória histórica, desafios atuais e propostas. São Paulo: Senac, 2003. 


\section{Educate and qualify: Eduquer et Qualifier: les ways and misdirection of chemins de l'éducation des education of youth and adult jeunes et adultes ouvriers workers \\ Résumé}

\begin{abstract}
This article presents some reflections on two basic approaches to educational qualification. First we deal with the conceptions of qualification subordinated to the social division of work and the adequacy of workforce to the historical needs of the different stages of expansion and consolidation of capital and of the social division of work. Afterwards we approach the theme under dialectical historical materialism. So, it will be presented a brief historical retrospect about qualification according to the needs imposed to the working class by capitalism. Then we deal with Marx's contributions to the comprehension of the theme. Finally we present some preliminary reflections on the importance of experience to the education of youth and adult workers from the perspective of a committed education to human emancipation.
\end{abstract}

Keywords: Education. Working Class. Qualification.
Dans cet article on présente des réflexions sur des questions qui concernent à la qualification, à partir de deux perspectives fondamentales. D'un côté, il s'aggit d'expliciter les conceptions de la qualification subordonnées à la division sociale du travail et à l'ajustement de la main-d'œuvre aux besoins des différentes étapes historiques de l'expansion et de la consolidation du capital. D'autre côté, on discute cette question à la lumière de la dialectique du matérialisme historique. Pour concrétiser cet objectif, on présente, d'abbord, une bref rétrospective historique du thème de la qualification et sa relation avec les besoins de la classe ouvrière, par rapport aux impositions du mode de production capitaliste. Ensuite, on discute les contributions du pensé Marxiste pour réfléchir sur cette thématique. Finalement, nous présenterons quelques réflexions préliminaires sur l'importance de l'expérience pour l'éducation des jeunes et adultes ouvriers, dans la perspective de l'éducation engagée avec l'émancipation humaine.

Mots-clés: Éducation. Classe ouvrière. Qualification. 
Sonia Maria Rummert

E-mail: rummert@uol.com.br

Recebido em: 31/2/2013

Versáo final recebida em: 27/5/2013

Aprovado em: 28/5/2013 